\title{
Lasting Effects of Intrauterine Exposure to Preeclampsia on Offspring and the Underlying Mechanism
}

\author{
Hui Qing Lu, MD ${ }^{1}$ Rong $\mathrm{Hu}, \mathrm{PhD}^{1}$ \\ ${ }^{1}$ Department of Obstetrics, Hospital of Obstetrics and Gynecology, \\ Address for correspondence Rong Hu, PHD, Hospital of Obstetrics and \\ Fudan University, Shanghai, China \\ Gynecology, Fudan University, No.419 Fangxie Road, Huangpu Division \\ Shanghai, Zip code: 200011, China (e-mail: hurongwy@sina.com).
}

Am J Perinatol Rep 2019;9:e275-e291.
Abstract
Keywords
- Preeclampsia Offspring
- cardiovascular system
- neurological disorders
- metabolism
- DOHaD

Preeclampsia is a common pregnancy complication which can have adverse impact on both mother and baby. In addition to the short term effects, a large body of epidemiological evidence has found preeclampsia can exert long-lasting effects on mother and offspring. Studies suggest that offspring exposed to preeclampsia are at a higher risk of developing cardiovascular, metabolic, and neurological diseases, as well as other diseases. However, studies investigating the underlying mechanism are limited, the exact mechanism still remains unclear. In this study, we will review the epidemiological evidence and studies exploring the mechanism underlying long-term effects of preeclampsia on offspring. Further studies should be targeted at this field so as to implement effective clinical management to prevent the exposed offspring from potential diseases.

Preeclampsia is a pregnancy-specific disorder, characterized by the new onset of hypertension after 20thgestational week, accompanied by one or more of the following conditions, such as proteinuria, thrombocytopenia, renal insufficiency, impaired liver function, pulmonary edema, and cerebral or visual symptoms. ${ }^{1}$ It affects 3 to $8 \%$ of pregnancy worldwide, which is a major cause of maternal and perinatal morbidity and mortality. The exact etiology of preeclampsia remains unknown. Various pathological mechanisms are involved in the development of preeclampsia including placental ischemia, hypoxia, imbalance between angiogenic and antiangiogenic factors, excessive inflammation, and production of autoantibodies. ${ }^{2,3}$ Preeclampsia is a multisystem disorder which can cause damage to various maternal organs and systems. Moreover, it is a major contributor to premature birth, intrauterine growth restriction, and small for gestational age. ${ }^{4}$ Currently, the most effective cure for this disease is the

(D) Hui Qing Lu's ORCID is https://orcid.org/0000-0002-6636-0338.

received

December 21, 2018 accepted after revision March 12, 2019 delivery of placenta and fetus, ${ }^{5}$ whereas the effect of preeclampsia doesn't cease. A line of evidence suggests that preeclampsia not only cause long-term adverse effects to the mother, including increased risks of developing hypertension and other cardiovascular and metabolic diseases, in later life but also affect the fetus's health immediately after delivery into adulthood, such as cardiovascular, metabolic, and neurological system. The mechanism through which preeclampsia exerts effects on offspring is not definitive. One widely accepted theory is Developmental Origins of Health and Disease (DOHaD) which was first proposed by David Barker. ${ }^{6}$ A favorable intrauterine environment is essential for the development and growth of fetus. The theory proposed that if the optimal environment is altered by pathological condition during a critical period of fetal development, the fetuses will adapt themselves to the unfavorable condition through developmental programming which can increase the risk of chronic diseases in later life. They found that cardiovascular diseases and type 2 diabetes derived from "developmental plasticity," as a result of under nutrition during fetal life. ${ }^{7}$ This review will
Copyright $\odot 2019$ by Thieme Medical Publishers, Inc., 333 Seventh Avenue, New York, NY 10001, USA. Tel: +1(212) 584-4662.
License terms

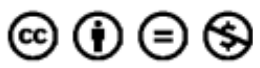

10.1055/s-0039-1695004. ISSN 2157-6998. 
focus on the epidemiological evidence of lasting effects of preeclampsia on offspring and current advances on the underlying mechanism.

\section{Cardiovascular Outcomes in Offspring Exposed to Preeclampsia Epidemiological Evidence}

We have found 15 relevant articles evaluating the cardiovascular effects of maternal preeclampsia on offspring ( - Table 1 ). Nine studies reported blood pressure data of offspring born after preeclampsia and normotensive pregnancy ${ }^{8-16}$ which had mixed results. Seven studies reported both increased systolic blood pressure (SBP) and diastolic blood pressure (DBP) in offspring exposed to maternal preeclampsia compared with normotensive pregnancy..$^{8-11,13-15}$ Participants, who included in these studies, were in their childhood, adolescence, or young adulthood. The increase in SBP are ranged from 0.14 to $2.3 \mathrm{~mm} \mathrm{Hg}$, while the range is from 0.03 to $1.71 \mathrm{~mm} \mathrm{Hg}$ in DBP. Whereas, one study found no significant differences in SBP and DBP between offspring of preeclampsia and normotensive pregnancy, aged 16 years. ${ }^{12}$ Alsnes et al found the increase in blood pressure of offspring aged 29 years, who were exposed to preeclampsia, was only existed when they were born from term pregnancy. ${ }^{8}$ Staley et al have followed up offspring from 7 to 18 years, both SBP and DBP were elevated in preeclampsia offspring, with the mean differences 1.22 and $0.80 \mathrm{~mm} \mathrm{Hg}$, respectively. ${ }^{10}$ The difference was consistent across childhood to age 18 years. This finding was similar with other two studies reported by Fraser et al and Lawlor et al. ${ }^{11,13}$ Offspring exposed to preeclampsia aged 10.7 years had $1.82 \mathrm{~mm} \mathrm{Hg}$ higher SBP and $1.40 \mathrm{~mm} \mathrm{Hg}$ higher DBP than those born after normal pregnancy after adjusting for maternal body mass index (BMI) and offspring age, sex, and BMI. Participants exposed to maternal preeclampsia aged 17 years had both higher SBP and DBP, 1.12 and $1.71 \mathrm{~mm} \mathrm{Hg}$, respectively, adjusting for maternal prepregnancy BMI and offspring age and sex. Geelhoed et al reported that offspring of preeclampsia aged 9 years from Avon longitudinal study had $2.05 \mathrm{~mm} \mathrm{Hg}$ higher SBP and $1.00 \mathrm{~mm} \mathrm{Hg}$ higher DBP independent of parental and own adiposity; ${ }^{14}$ nonetheless, the difference attenuated to null after controlling for birth weight and gestational age, indicating that the increase in blood pressure of offspring was exposed to preeclampsia may be at least partly mediated by the effect of preeclampsia on intrauterine growth restriction. Furthermore, there was a study reporting increased pulmonary artery pressure of offspring exposed to preeclampsia compared with normal pregnancy who were living at the same high altitude ${ }^{16}(p<0.001)$.

Two studies have compared BMI. One study found that offspring aged 29 years of preeclampsia born from term pregnancy had $0.93 \mathrm{~kg} / \mathrm{m}^{2}$ higher BMI than those born term of normal pregnancy. ${ }^{8}$ Another study reported $2.1 \mathrm{~kg} / \mathrm{m}^{2}$ higher BMI in preeclampsia offspring aged 17 years $(p<0.05){ }^{11}$

Five studies investigated the cardiac structure and function in offspring. ${ }^{17-21}$ Timpka et al reported that offspring aged 17.7 years born after preeclampsia had 0.025 greater cardiac relative wall thickness and $0.9 \mathrm{~mL}$ smaller left ventricular end- diastolic volume than normotensive pregnancy, ${ }^{18}$ which is a concentric type of remodeling, associated with higher risk of coronary heart disease and stroke in adulthood. Nonetheless, Kajantie et al found no evidence that preeclampsia was associated with coronary heart disease in the offspring. ${ }^{21}$ The authors believed that a small increase in the risk of coronary heart diseases couldn't be excluded because of the limitation of sample size. Large scale of studies is needed to confirm the relationship between preeclampsia and the risk of coronary heart diseases in the offspring. Boyd et al reported increased risk of congenital heart defect in offspring of preeclampsia compared with normotensive pregnancy. Offspring congenital heart defects were strongly associated with early preterm, late preterm, and term preeclampsia, odds ratio (OR) were 7.0 (95\% confidence interval [CI]: 6.11-8.03), 2.82 (95\% CI: 2.38-3.34), 1.16 (95\% CI: 1.06-1.27), respectively. ${ }^{17}$

Auger et al also described a positive association between preeclampsia and congenital heart defects in infants; a total of $1,942,072$ neonates were included. ${ }^{19}$ They found that the prevalence of congenital heart defects was higher in neonates of preeclamptic women compared with those without preeclampsia, 16.7/1,000 and 8.6/1,000, respectively, especially the early-onset preeclampsia which had significantly higher prevalence of both critical and noncritical congenital heart defects(364.4/100,000 vs. 75.6/100,000 and 7306.9/100,000 vs. 789.2/100,000). Brodwall et al reported that preeclampsia, especially early-onset preeclampsia, was associated with the increased risk of severe congenital heart defects (relative risk preeclampsia, 1.3 [95\% Cl: 1.1-1.5]; early-onset preeclampsia, 2.8 [95\%CI: $1.8-4.4]) .^{20}$

Two studies evaluated offspring vascular function. The endothelial function was assessed by brachial artery flowmediated dilatation (FMD). Arterial stiffness was assessed by carotid to radial pulse wave velocity (PWV) and brachial artery distensibility coefficient (DC). The results were inconsistent. Lawlor et al found no statistically significant differences in vascular function including flow-mediated dilatation absolute, pulse wave velocity, and distensibility coefficient of offspring aged 10.7 years between preeclampsia and normotensive pregnancy. ${ }^{13}$ Whereas, Jayet et al reported that offspring in adolescence, who were living at high altitude, born after preeclampsia had lower FMD of the brachial artery than normal pregnancy (preeclampsia: $6.3 \pm 1.2 \%$; normal pregnancy: $8.3 \pm 1.4 \% . p<0.0001) .{ }^{16}$ The former study involved large scale of population $(n=102$ with preeclampsia and 3,781 controls with normotensive pregnancy) and was based on general population not living at high altitude. The latter one was smaller and based on selected population who lived at high altitude. The different results might be attributed to the limitation of the sample size. It's also possible that the stress on the vascular system at high altitude allowed associations to emerge, besides, the alteration in vascular function of offspring of preeclampsia might emerge until adolescence.

Kajantie et al found that offspring exposed to preeclampsia born in 1934 to 1944 from Helsinki cohort study were at 1.9 times increased risk of stroke in adult life compared with normal pregnancy after adjusting for birth weight and gestational age. ${ }^{21}$ 


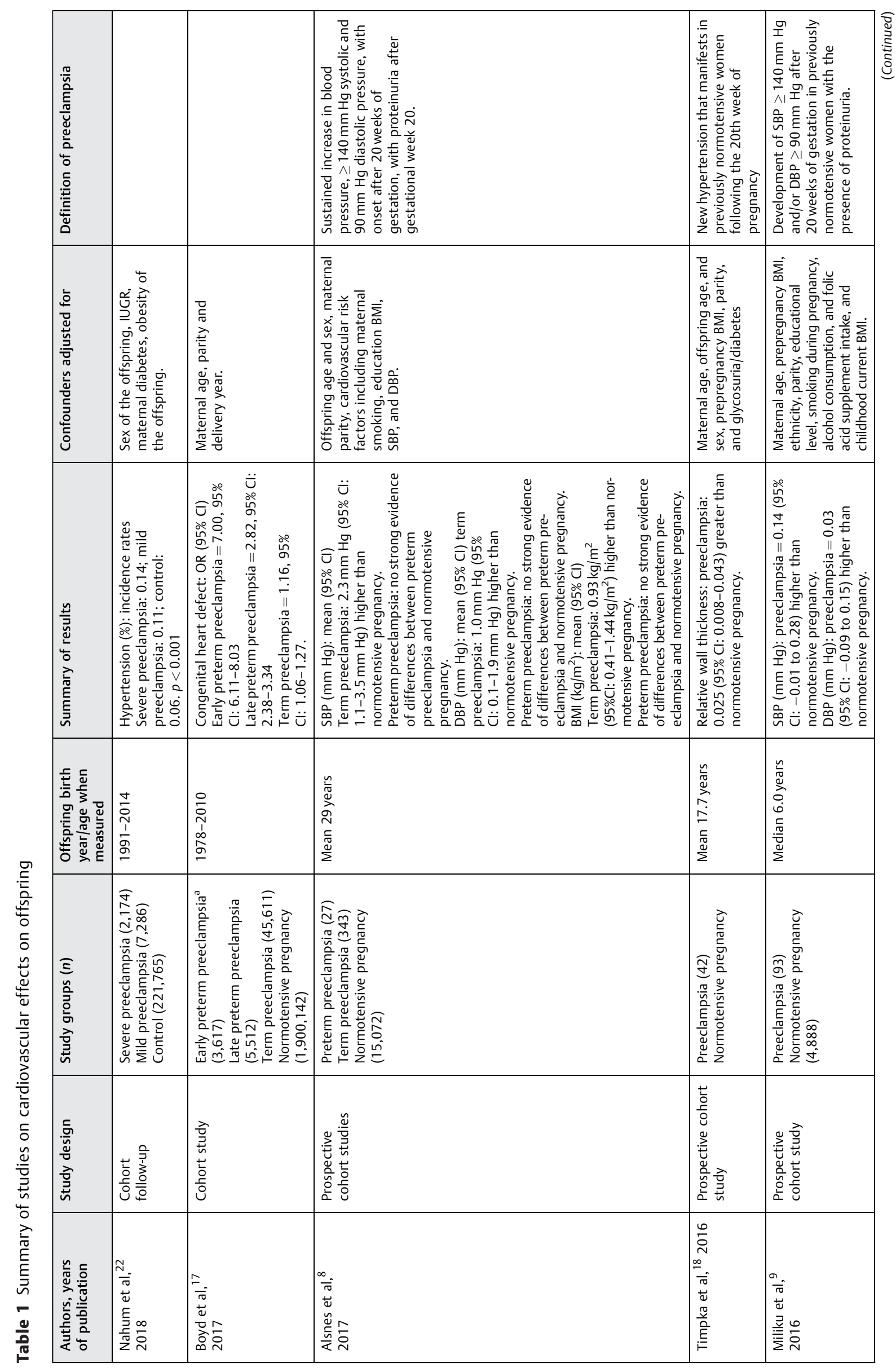




\begin{tabular}{|c|c|c|c|c|c|c|}
\hline 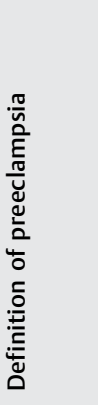 & 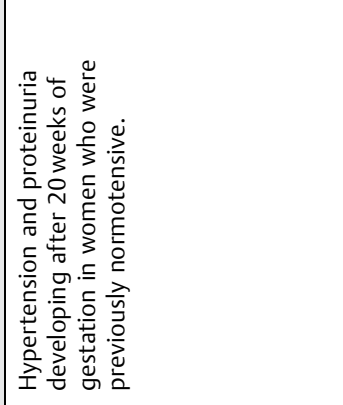 & 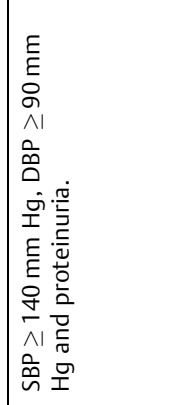 & 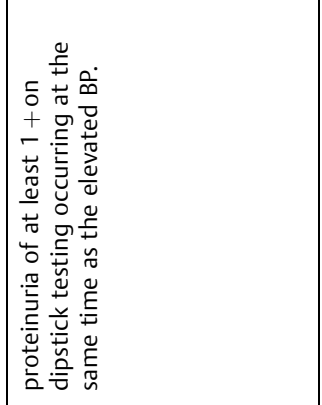 & 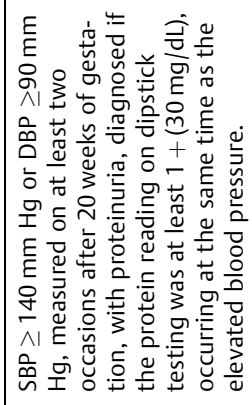 & 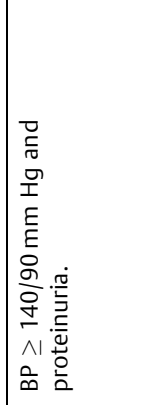 & 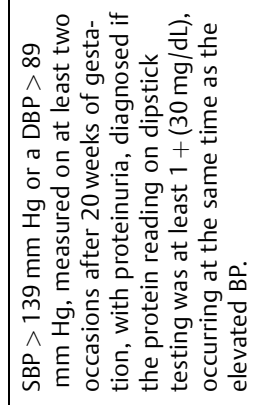 \\
\hline 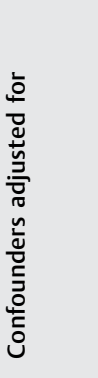 & 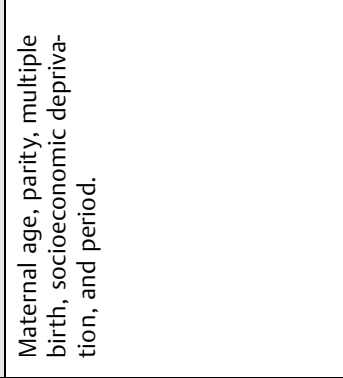 & 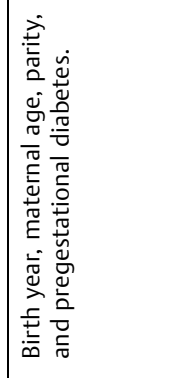 & 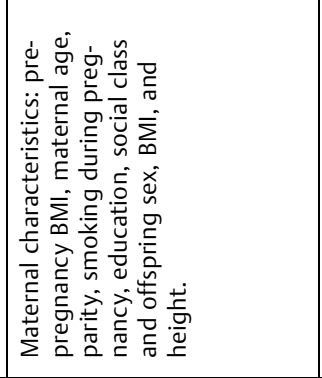 & 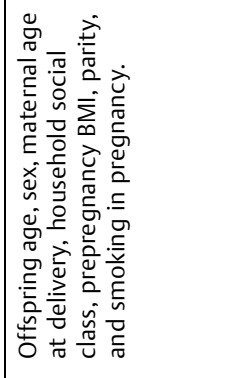 & 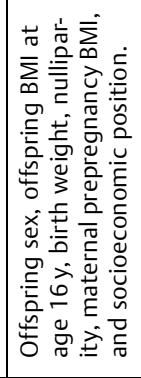 & 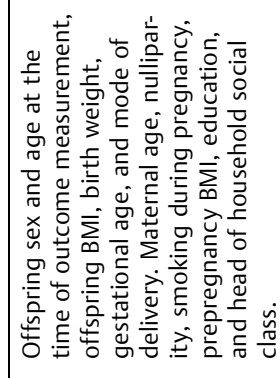 \\
\hline 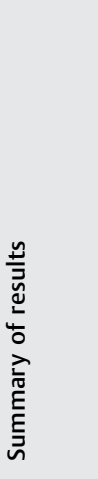 & 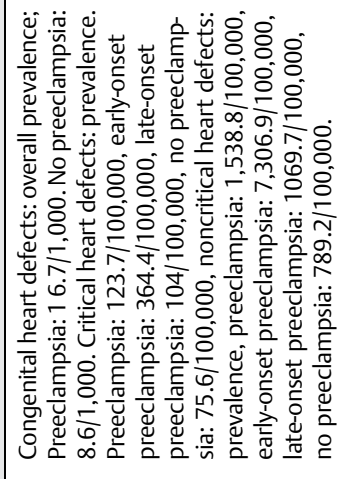 & 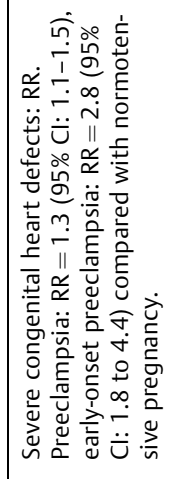 & 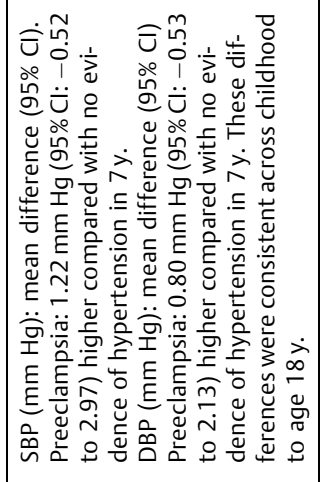 & 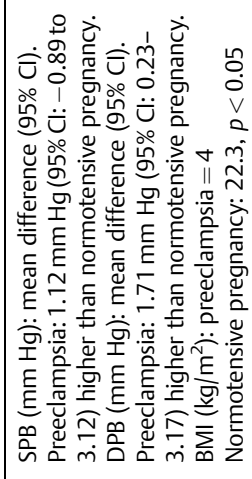 & 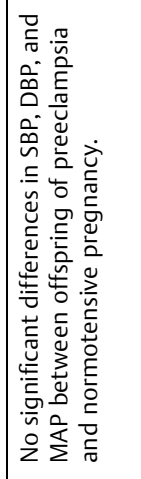 & 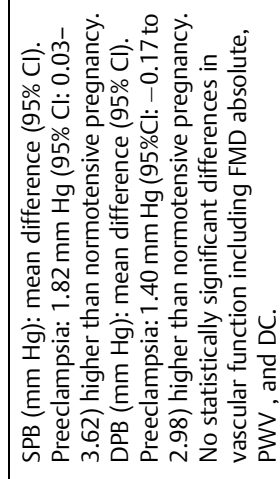 \\
\hline 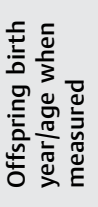 & & 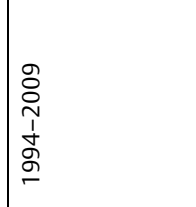 & 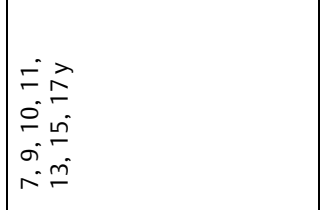 & 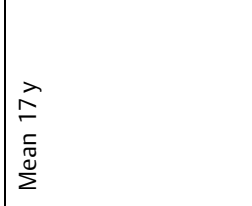 & $\stackrel{\vec{\sigma}}{ }$ & $\begin{array}{l}\lambda \\
\hat{0} \\
0\end{array}$ \\
\hline 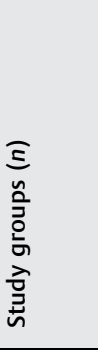 & 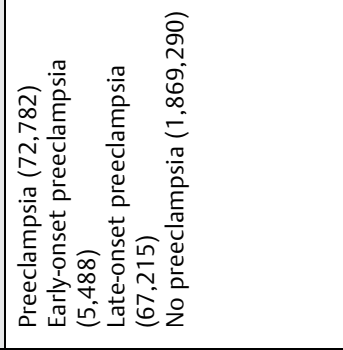 & 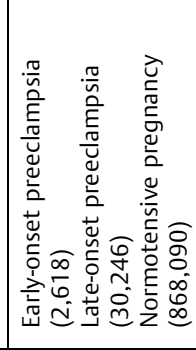 & 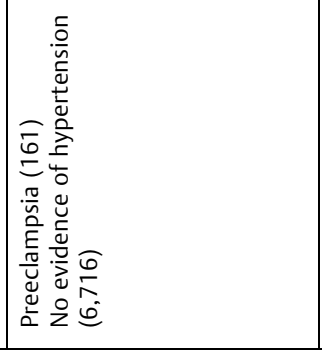 & 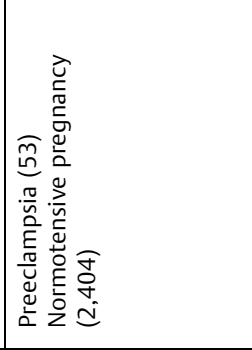 & 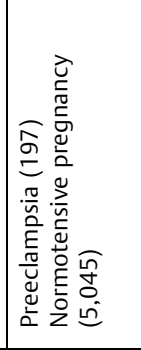 & 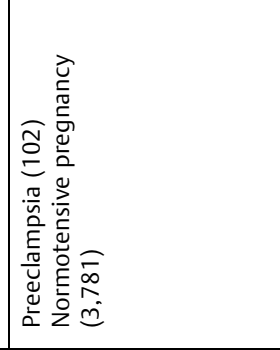 \\
\hline 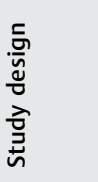 & 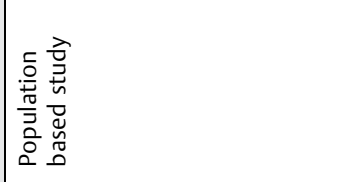 & 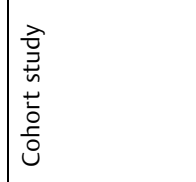 & 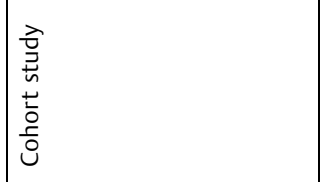 & 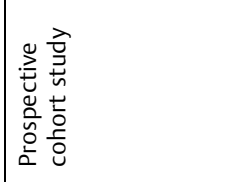 & 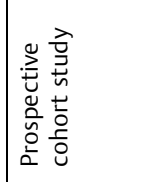 & 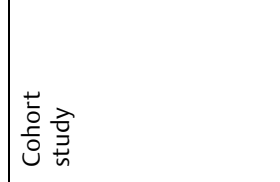 \\
\hline 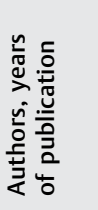 & 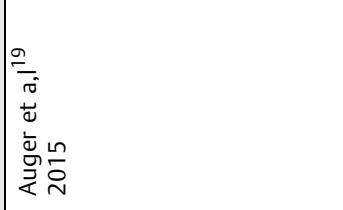 & 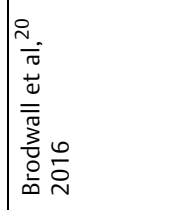 & 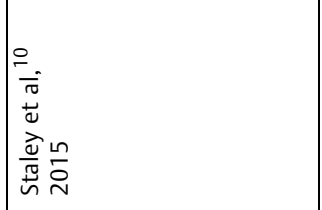 & 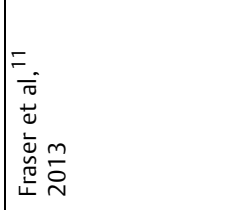 & 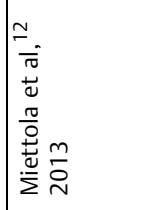 & 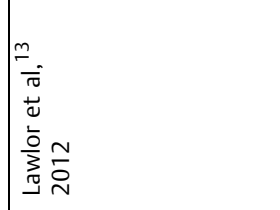 \\
\hline
\end{tabular}



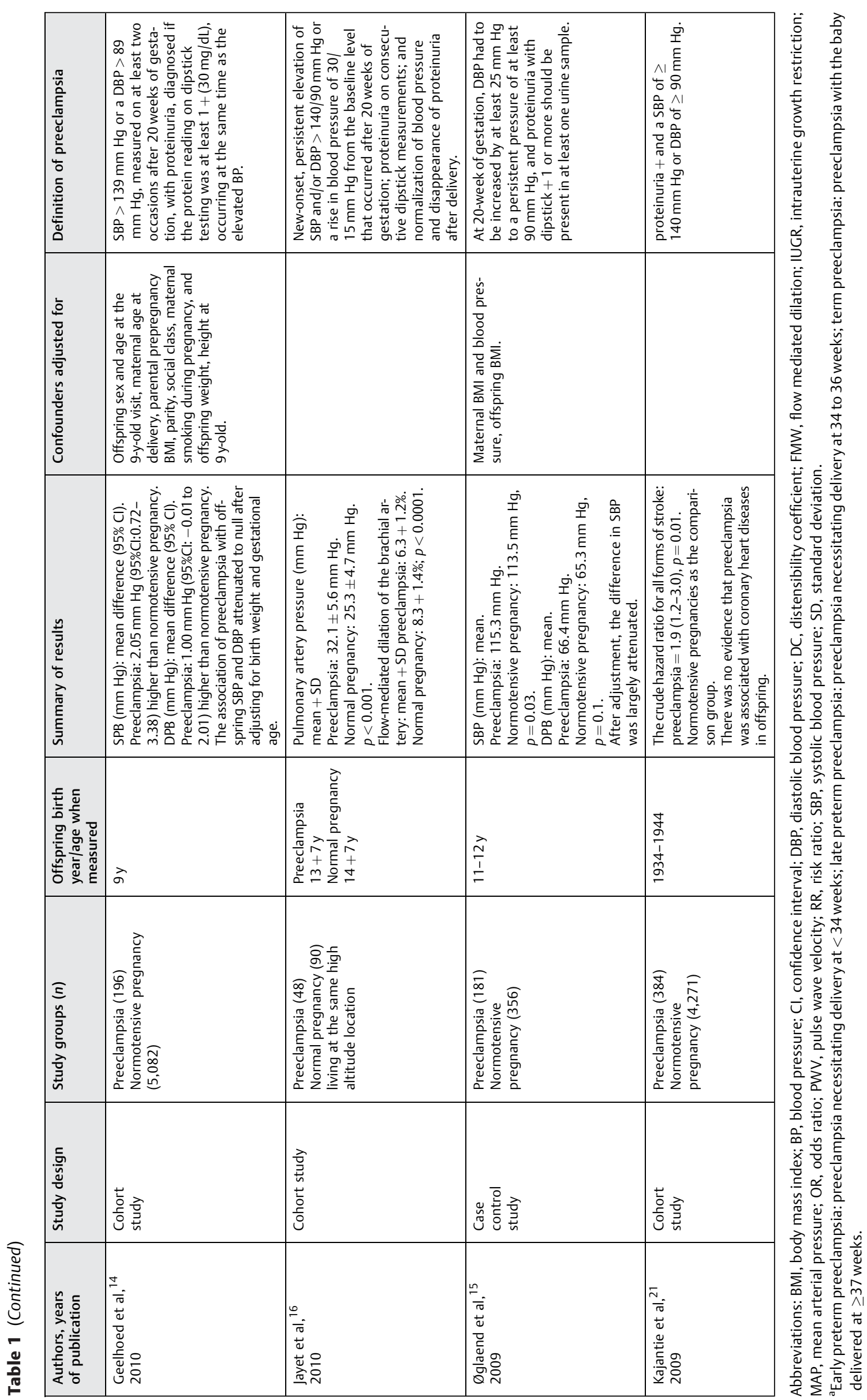
Nahum et al reported that offspring of preeclampsia were at higher risk of developing hypertension compared with normotensive pregnancy (incidence rate of hypertension: severe preeclampsia: 0.14 ; mild preeclampsia: 0.11 ; control: 0.06 ; $p<0.001)^{22}$

\section{The Underlying Mechanism}

The mechanism underlying adverse cardiovascular outcome in offspring may be a complex interplay of genetic, shared environmental factors, and fetal programming. It has already been known that genetic factors play a crucial part in the development of preeclampsia which exhibit the familial clusters with the heritability estimated to be $47 \%{ }^{23}$ Thus genetic factors may be inherited by the offspring predisposing them to preeclampsia and cardiovascular disease in later life. In addition, environmental factors, shared by the mother and offspring, may also lead to the adverse effects on offspring. ${ }^{24}$ However, Jayet et al found that offspring exposed to preeclampsia had approximately $30 \%$ higher pulmonary artery pressure and impaired vascular function while their siblings born after the normal pregnancy had normal vascular function which cannot be explained only by genetic components and shared environmental factors. ${ }^{16}$ The findings above revealed that the pathological event in the uterus can lead to impaired vascular function and pulmonary dysfunction. The underlying mechanism through which chronic diseases are initiated might be alteration of gene expression, ${ }^{25}$ changes in the kidney growth ${ }^{26}$ and alterations in homeostatic set points including the hypothalamic-pituitary-adrenal axis, ${ }^{27}$ vascular structure and sensitivity, ${ }^{28}$ rennin-angiotensin system (RAS) ${ }^{29}$ and metabolic and hormonal set-points ${ }^{30}$ which can make the affected system more vulnerable to adverse influences in postnatal life.

Vascular and endothelia dysfunction are known to play a critical role in the development and progression of hypertension. ${ }^{31}$ Jayet et al showed an impaired vascular function of offspring compared with those of normal pregnancy. ${ }^{16}$ Rodent studies also found that vascular function was altered in the offspring of mice with soluble fms-like tyrosine kinase-1 (sFlt-1) induced preeclampsia-like phenotype. ${ }^{28}$ Antiangiogenic state has been found in adulthood of offspring born after preeclampsia with elevated level of plasma sFlt- 1 and soluble Endoglin (Eng), related to the increase in blood pressure. $^{32}$ The antiangiogenic state also be observed in heart defects. ${ }^{33}$ This shared pathway may account for the increased risk of congenital heart defects in neonate born after preeclampsia. A study shows that the pathology of preeclampsia begins as early as the start of the pregnancy, near the time of the morphogenesis of fetal heart. ${ }^{34}$

The kidney can be programmed by various perinatal insults, such as placental insufficiency. Decreased nephron numbers and subsequent impaired blood pressure regulation in offspring has always been found in rodent model with placental insufficiency. ${ }^{26,35}$ Decreased nephron numbers can influence blood pressure through impairing the ability of kidney to maintain sodium homeostasis due to the imbalance in excretory load and capacity. Singh et al found that decreased excretory capacity could arise from altered expression of renal sodium transporters and channels. ${ }^{36}$ In addition, the programming of RAS and sympathetic nerve system (SNS) may also be involved in offspring hypertension. Placental insufficiency has been reported to affect RAS programming 37,38 and animal models demonstrated increased sensitivity to anigiotensin II. ${ }^{39}$ Additionally, blockage of RAS by angiotensin-converting enzyme inhibitor(ACEI) or angiotensin II type 1 receptor (AT1) blockade could prevent the development of hypertension in adult offspring of dams with reduced uterine perfusion pressure (RUPP), ${ }^{40,41}$ suggesting the involvement of RAS in fetal programming. Increased SNS activity is tightly associated with hypertension. Activation of SNS has been found in low-birth-weight human and animal models of placental deficiency. ${ }^{42,43}$ Chronic exposure to hypoxia can stimulate hyperinnervation and alterations in renal nerve activity. ${ }^{44,45}$ Consequently, placental insufficiency and subsequent hypoxia result in altered renal nerve development and impaired blood pressure in offspring. Researchers discovered that renal denervation normalized hypertension in offspring exposed to placental insufficiency. ${ }^{46}$ These studies provide evidence for the programming of kidney, RAS, and SNS in offspring hypertension due to poor intrauterine environment.

Interestingly, there is a line of evidence that prenatal exposure to elevated level of testosterone, observed in preeclamptic women, ${ }^{30,47}$ is associated with increased blood pressure during adult life in female offspring. ${ }^{48}$ Animal studies found that elevated level of androgen during pregnancy can lead to hyperactivity of hypothalamic-pituitary-gonadal axis and alteration in steroidogenic genes expression in the gonads of the offspring, resulting in increased production of testosterone. ${ }^{49,50}$ More et al showed that prenatal exposure to elevated testosterone led to a decrease in the expression of Cyp11b2 resulting in reduced plasma aldosterone level of offspring, but the plasma volume and balance between $\mathrm{Na}^{+}$and $\mathrm{K}^{+}$were normal. ${ }^{51}$ However, the level of plasma vasopressin, angiotensin II, vascular responsiveness to angiotensin II, and arterial pressure were increased in adult female offspring exposed to higher testosterone which might serve as compensatory response to maintain plasma volume and the balance between $\mathrm{Na}^{+}$and $\mathrm{K}^{+}$, in the meantime mediate hypertension in adult female offspring prenatally exposed to aldosterone. According to the mentioned above, prenatal exposure to elevated testosterone in pregnancy with preeclampsia might be a possible mechanism through which preeclampsia is associated with increased risk of hypertension in adult life of offspring. Henley et al showed that the level of adrenocorticotropic-hormone (ACTH) and cortisol were significantly elevated in 17-year-old offspring of women with preeclampsia, indicating that the activity of Hypothalamic-Pituitary-Adrenal (HPA) axis was reprogrammed due to the intrauterine exposure to preeclampsia, persisting into adulthood, which might account for the elevated blood pressure of offspring exposed to preeclampsia. ${ }^{27}$

Epigenetic changes can be induced when the fetus is exposed to environmental stimuli, especially in the critical window of development. ${ }^{52}$ The epigenetic changes include DNA methylation, histone modification, and the expression of noncoding RNA. DNA methylation is a covalent modification of gene with the stability in a heritable transgenerational way. ${ }^{53}$ 
Methylation of critical regulatory sites of gene-like gene promoters can lead to down regulation of the expression of gene. There are some studies analyzing DNA methylation of genes associated with the fetal growth and development which are sensitive to the environmental perturbations in cord blood cells. Researchers found the hypomethylation of the promoter region of $11-\beta$-hydroxysteroid-dehydrogenase-2enzyme(11- $\beta$-HSD-2) in cord blood sample from women with preeclampsia. ${ }^{54}$ Hypomethylation was observed in the differentially methylated regions of insulin-like growth factor 2 (IGF-2), which were crucial for the regulation of imprinted genes. ${ }^{55}$ On the contrary, there are studies showing a decreased level of gene expression of $11-\beta$-HSD-2 and IGF-2 in placenta from women with preeclampsia. ${ }^{55,56}$ Researchers speculate that the discrepancy between the hypomethylation and down regulation of the genes might be a compensatory mechanism. However, it can also be an atypical decrease in the gene expression leading to the metabolic maladaptation. Recently, researchers conducted a genome-scale methylation analysis of cord blood DNAs associated with early-onset preeclampsia. They found hypomethylation or hypermethylation in different subsets of genes involved in lipid regulation and inflammation, suggesting a possible link between maternal preeclampsia and increased risks of cardiometabolic diseases in offspring. ${ }^{57}$ Wang et al have showed alterations in methylation level of differentially methylated regions (DMR) of mesoderm specific transcript (MEST) related to adipocyte differentiation and obesity and DLK1 (Delta like non-canonical Notch ligand 1) encoding a protein preadipocye factor-1 (Pref1) which is an inhibitor of adipocyte differentiation in placenta of preeclampsia ${ }^{58}$ which might the mechanism through which preeclampsia is associated with increased risk of metabolic disorder in the later life of offspring. The epigenetic modulation can also occur in the fetus's renin-angiotensin-aldosterone system (RAAS). Human studies discovered that there were decreases in the DNA methylation of genes involved in RAAS in placentas of women exposed to early-onset preeclampsia. ${ }^{59}$ Furthermore, researchers observed alterations in the level of cardiovascular and cerebrovascular diseases associated micro-RNAs expression in the umbilical cord blood of preeclampsia compared with normal pregnancy. ${ }^{60}$ MicroRNAs can regulate the expression of gene at the posttranscriptional level through the pathway of RNA interference. It can control gene expression through the cooperation with transcriptional factors as well. Micro-RNA expression changes in umbilical cord blood induced by preeclampsia might result from placenta dysfunctional and lead to the onset of cardiovascular and cerebrovascular diseases in later life of offspring. Recently, researchers found the downregulation of 16 microRNAs in fetal endothelial cells of preeclampsia including miR$29 \mathrm{a} / \mathrm{c}-3 \mathrm{p}^{25}$ which can lead to impaired fetal endothelial cells immigration through the disturbance of the FGF2-stimulated PI3K-AKT1 pathway, indicating that downregulation of microRNAs in fetal endothelial cells in preeclampsia might be the result of early fetal programming associated with the increased risks of cardiovascular diseases in later life of offspring since the impaired angiogenesis is a critical characteristic of cardiovascular diseases.
Nonetheless, a recent epidemiological study cast doubt on the hypothesis of "developmental programming." The population-based study in Norway involving 15,778 participants showed that young adults (mean age: 29 years) born after pregnancy, complicated by preeclampsia, had higher SBP and DBP, an increase in BMI, and wilder waist circumference compared with offspring of normotensive pregnancies. However, after adjustment for maternal factors including maternal BMI and maternal blood pressure, the differences are strongly attenuated. ${ }^{8}$ Intriguingly, researchers found that their siblings who were born after normotensive pregnancy had an identical cardiovascular risk profiles as those born after hypertension in pregnancy. The findings are in favor of the idea that most of the increased cardiovascular risk in offspring may be attributed to shared genetic and environmental factors. However, this study can't exclude the effects of intrauterine exposure to maternal hypertension. Lazdam et al found that offspring born after early-onset preeclampsia had higher SBP in childhood compared with those exposed to late-onset preeclampsia, suggesting the severity and duration of fetal exposure to maternal hypertension in pregnancy is critical for the cardiovascular outcome in offspring. ${ }^{61}$ The study by Alsnes et al $^{8}$ didn't clarify the duration of exposure and short-term exposure to maternal hypertension in pregnancy may have minimal effects on long-term cardiovascular outcomes in offspring compared with genetic and environmental factors. - Fig. 1 demonstrated the complex interplay of genetic, environmental factors, and fetal programming on the development of offspring hypertension.

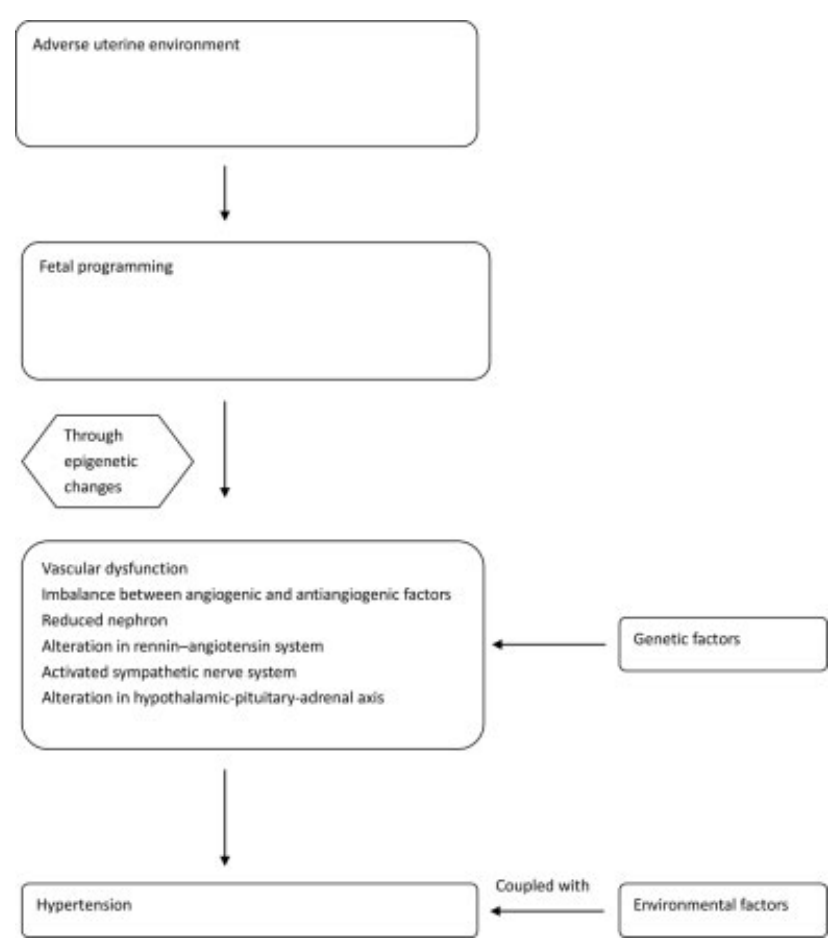

Fig. 1 Mechanism underlying the development of hypertension in the offspring exposed to preeclampsia. Preeclampsia cause an adverse uterine environment which will lead to fetal programming. Epigenetic change is critical in programming resulting in disturbances in various pathways, coupled with the effects of genetic and environment factors, leading to hypertension in offspring. 


\section{Metabolic Outcome in Offspring. Epidemiological Evidence}

Studies investigating metabolic effects indicated that preeclampsia has no significant effects on offspring (- Table 2 ). Five studies reported lipid profile between offspring of preeclampsia and normotensive pregnancy aged 10 to 17 years, ${ }^{8,11-13,62}$ four of which found no statistically significant difference in total cholesterol, high-density lipoprotein (HDL) cholesterol, non-HDL cholesterol, ${ }^{11-13,62}$ two of which found no statistically significant difference in triglycerides and lipoprotein, apoA1, apoB. ${ }^{12,13}$ Only one study reported that offspring aged 29 years exposed to term preeclampsia had 0.14 (95\% CI: 0.03-0.25) mmol/L higher non-HDL cholesterol and 0.13 (95\% CI: 0.06-0.21) mmol/L higher serum concentration of triglycerides than term normotensive pregnancy. ${ }^{8}$

Five studies were involved in glucose metabolism. The results were consistent. There were no differences in the concentration of insulin and glucose between offspring of preeclamptic women and those of women with normal pregnancy in childhood and adolescence. ${ }^{11,12,62}$ In accordance with the results above, a recent study showed that insulin sensitivity measured by QUICKI (the Quantitative Insulin Sensitivity Check Index) in 12-year-old offspring born after preeclampsia didn't differ from those from normotensive pregnancy. ${ }^{63}$ Kajantie et al found that there was no association between the risk of developing type 2 diabetes in offspring aged from 50 to 61 years and maternal nonsevere or severe preeclampsia, ${ }^{64}$ but it should be interpreted with caution due to limited sample size of preeclampsia.

\section{Neurological Effects in Offspring}

\section{Preeclampsia and ASD/ADHD in Offspring Epidemiological Evidence}

We have found four studies investigating the association between preeclampsia and offspring autism spectrum disorder (ASD; - Table 3). The epidemiological studies have reached an agreement and demonstrated a statistically significant increase in the odds of ASD in offspring exposed to preeclampsia. The OR ranges from 1.64 to 2.36 . $^{65-68}$ Walker et al suggested that the risk of ASD increased with greater severity of preeclampsia(log odds of ASD relative to typical development [TD] in relation to preeclampsia severity: mild preeclampsia,1.69; severe preeclampsia, 2.04; $p=0.0188) .{ }^{65}$ Five studies explored the risk of attention deficit hyperactivity disorder (ADHD) among offspring exposed to maternal preeclampsia( - Table 3) ${ }^{69-73}$ Four studies with a large number of participants demonstrated a positive association of preeclampsia and offspring ADHD with OR ranging from 1.19 to $1.34 .^{69-71,73}$ Silva et al found that preeclampsia was associated with increased risk of ADHD among offspring and female offspring are at higher risk than male offspring (OR: female, 1.28 [95\% CI: 1.05-1.56]; male, 1.15 [95\% CI: $1.03-1.27]) .{ }^{69}$ In contrast, Amiri et al showed a protective association between preeclampsia and ADHD which didn't show statistical significance and take potential confounder into account. ${ }^{72}$

\section{The Underlying Mechanism}

Although the mechanism underlying the association of preeclampsia and increased risks of ASD/ADHD in offspring is not clearly identified, insufficient uteroplacental perfusion, placental ischemia, hypoxia, limited nutrient, and oxidative stress and inflammation state in preeclampsia may play a role in the pathogenesis of ASD/ADHD. Evidence from animal studies and neuroimaging studies reported adverse effects of placental ischemia on fetal brain development. ${ }^{74,75} \mathrm{~A}$ line of studies have demonstrated that ADHD is associated with brain abnormalities including decreased global cortical thickness, smaller total brain, and gray matter volume. ${ }^{76,77}$ In consistent with these studies, an animal study reported long-term attention deficits in rats that underwent hypoxicischemia, which exhibited global brain atrophy. ${ }^{78}$ In recent years, interleukin-6 (IL-6) has raised researcher's awareness. It is an inflammatory cytokines, which can cross the placenta, and have the potential to regulate fetus's neuronal proliferation, differentiation, and function. A population-based study involving 1 million pregnancy showed that higher levels of C-reactive protein which is an inflammatory biomarker in preeclampsia is associated with a $43 \%$ increase in the risk of ASD in offspring. Researchers found that exposure of neuron from Sprague-Dawley rat embryos to serum of women with preeclampsia can increase neuron growth. ${ }^{79}$ Although, this finding cannot directly suggest a causal relationship with the risk of autism, it indicates that circulating factors in maternal serum of preeclampsia can alter the pattern of fetal neuronal growth. Recently, an literature published in Science discovered that elevated level of maternal IL-17a in the rodent maternal immune activation (MIA) model can lead to cortical defects and associated autism behavior in the offspring. ${ }^{80}$ It has been known to us that IL-17 levels are increased in the maternal circulation and the maternal immune response is disturbed with a shift to proinflammatory state in preeclampsia. ${ }^{81}$ Therefore, it is reasonable to speculate that the disturbance in immune response in women with preeclampsia may play a role in the neurodevelopmental outcome in the offspring. Future research is needed to clarify whether IL-17 is the underlying intermediate through which preeclampsia affect the offspring's neurodevelopment. It is worth noting that IL-6 has been observed to mediate the effect of MIA on the offspring suggesting IL-6 signaling in placenta can control fetal brain development and behavior. ${ }^{82}$ IL- 6 activation can serve to relay inflammatory signals to the fetal brain and exert effects on the behaviors and neuropathologies associated with ASDs. In consistent with this, Curran et al found four of five preeclampsia samples those had elevated IL-6 levels compared with control groups. ${ }^{79}$ There are other studies investigating the role of maternal cytokines. Jones et al found that mothers of children diagnosed with autism with intellectual disability had increased levels of cytokines and chemokines including IL-6, interferon-r, IL-1a, granulocyte macrophage colony-stimulating factors in midgestation, indicating the potential role of abnormal immune response in pregnancy which are commonly observed in preeclampsia in the increased risk of autism. ${ }^{83}$ 


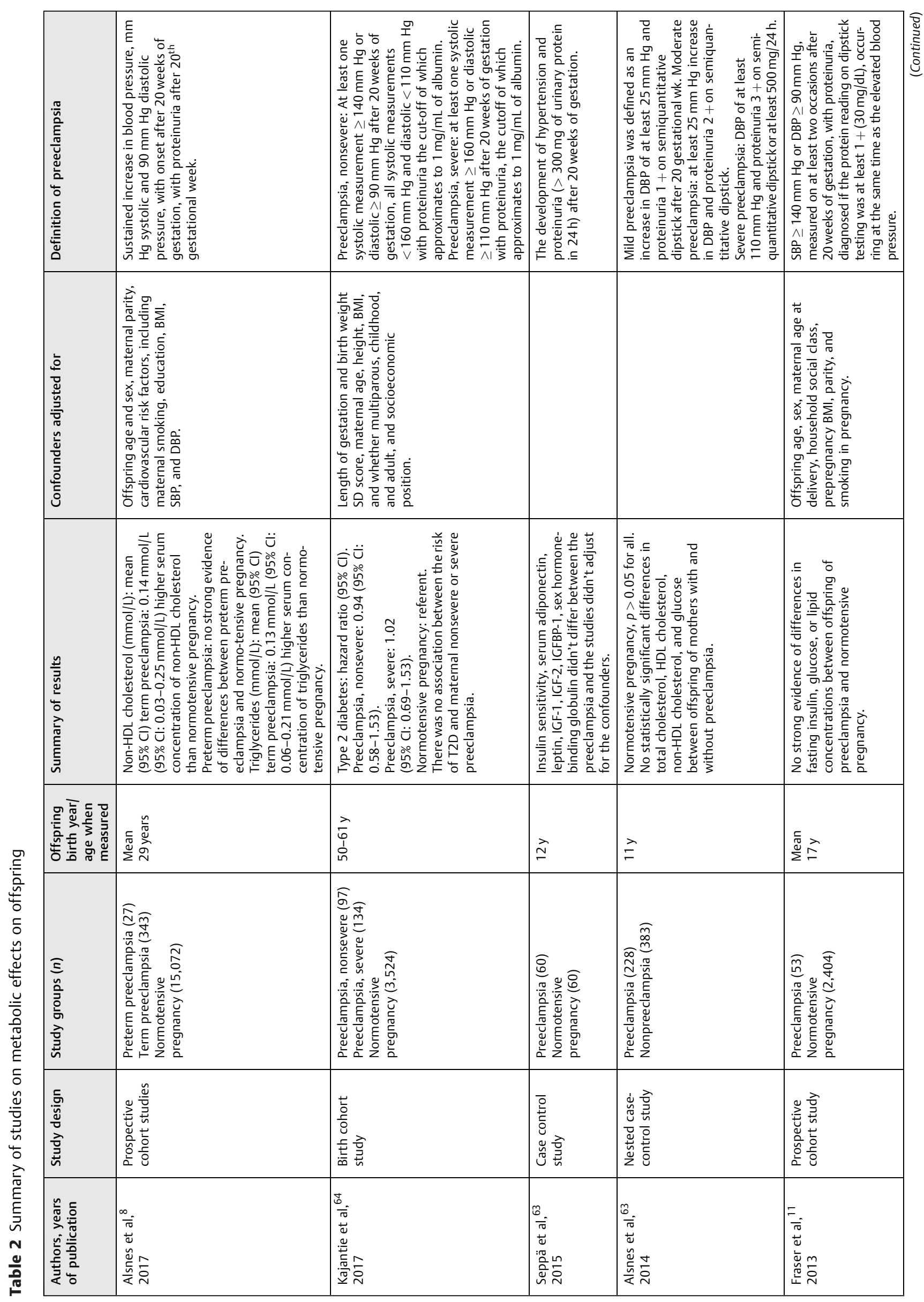




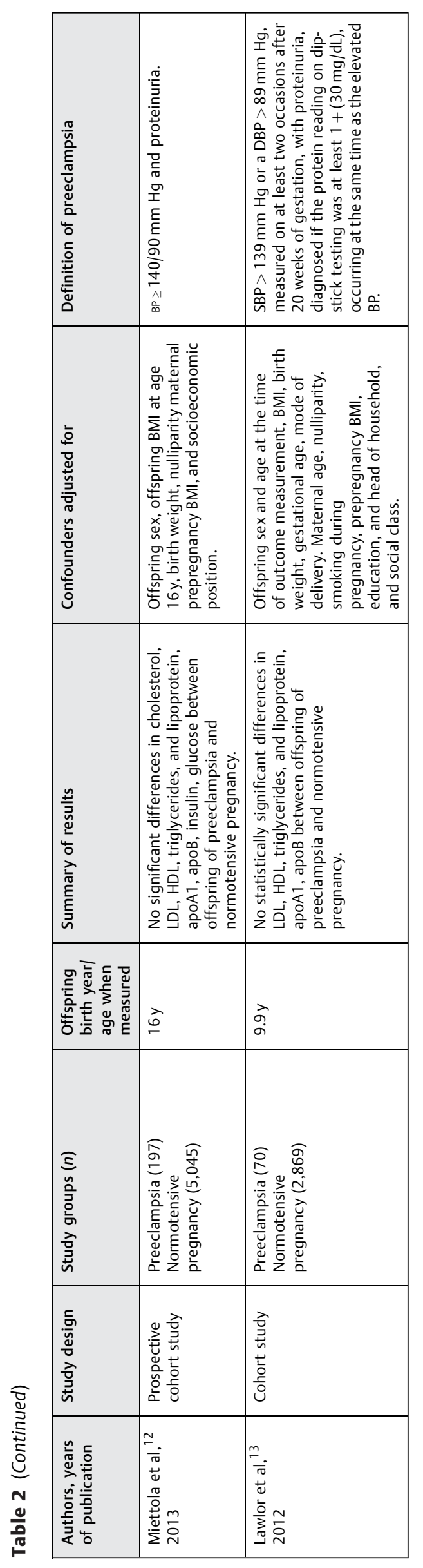

\section{Preeclampsia and Cognitive Impairment in Offspring Epidemiological Evidence}

Six studies analyzed the cognitive function of offspring exposed to maternal preeclampsia ( - Table 3) ${ }^{84-89}$ All of them showed that intrauterine exposure to preeclampsia had an adverse effect on offspring cognitive function after controlling for prenatal and demographic covariates. Rätsep et al evaluated the cognitive function among children aged 7 to 10 years who were exposed to preeclampsia and they found those children had an impairment in working memory and visuospatial processing. ${ }^{84}$ Warshafsky et al discovered that offspring aged 1 to 5 years exposed to severe preeclampsia exhibited lower sociocognitive and executive functioning development compared with those born after normal pregnancy. ${ }^{85}$ Morsing and Maršál calculated intelligence quotient (IQ) among offspring aged 5 to 8 years born very preterm. ${ }^{87}$ Those exposed to preeclampsia had statistically significantly lower verbal IQ and full scale IQ compared with those who were not exposed to preeclampsia (verbal IQ: $74 \pm 16$ vs. $89 \pm 15, p=0.013$; full scale IQ: $70 \pm 19$ vs. $83 \pm 14$, $p=0.029)$. In consistent with these studies, Griffith et al found that preeclampsia was associated with increased risk of intellectual disability among children at 3 to 5 years (OR: 1.579 [95\% CI: $1.334-1.870]) .{ }^{88}$ Ehrenstein et al investigated the association of preeclampsia and offspring cognitive function at 18 to 19 years and they found offspring exposed to preeclampsia were at increased risk of low cognitive function which was defined as $\mathrm{IQ}<85$ (prevalence ratio: 1.32 [95\%CI: $1.08-1.62$ ]). ${ }^{89}$ Tuovinen et al evaluated cognitive function in participants from Helsinki birth cohort study aged 69.3 years. ${ }^{86}$ Offspring born after preeclampsia were at increased risk of having impairment in memory and cognition (OR: 3.92 [95\%CI: 1.39-11.04], $p=0.01$ ) compared with normotensive pregnancy.

\section{The Underlying Mechanism}

A rodent study found that the spatial learning and memory ability was impaired in offspring of preeclamptic rat model, which might be associated with the defective neurogenesis in offspring hippocampus observed in this study. ${ }^{90,91} \mathrm{Zhu}$ et al showed that 8-week-old offspring of preeclampsia-like rat induced by NG-nitro-L-arginine methyl ester(L-NAME) had impaired cognitive ability and had increased expression of glucocorticoid receptor (GR) in the hippocampus ${ }^{92}$ which might be the underlying mechanism of the impaired cognitive ability in offspring of preeclampsia.

There is a literature demonstrating the positive effects of improved nutrition on the brain function..$^{93}$ Nutrients play an important role in the brain development and the regulation of levels of neurotrophins. ${ }^{94,95}$ Neurotrophins have been known to be critical in the maintenance of brain plasticity and cognitive function. Recently, a study has examined the levels of neurotrophins in the offspring of pregnancy-induced hypertension rat. Researchers found that the level of BDNF (brainderived neurotrophins factor) was lower in the cortex of offspring in pregnancy induced hypertension (PIH) group compared with normotensive group and the cognitive performance was impaired. In another group, in which researchers 


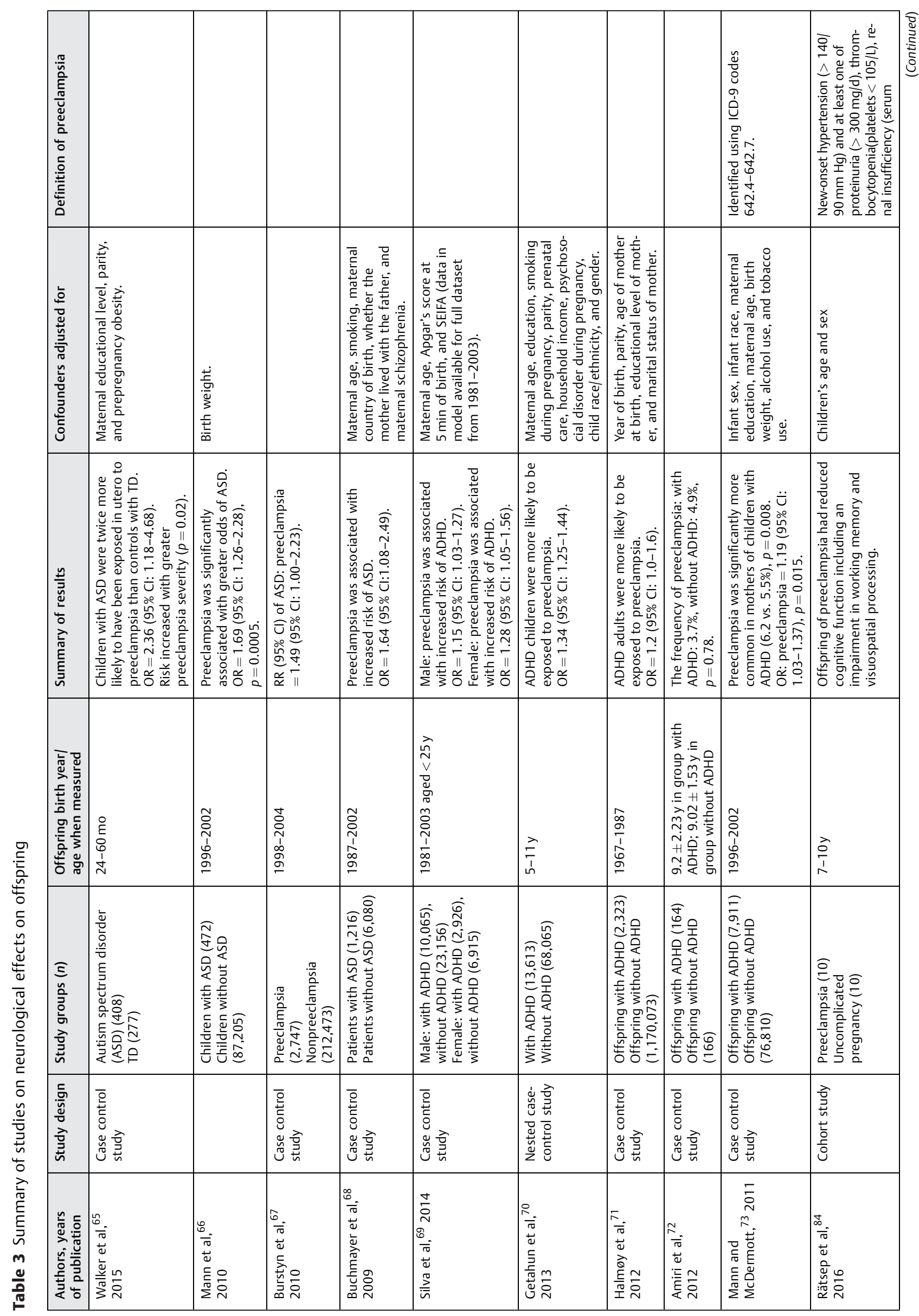




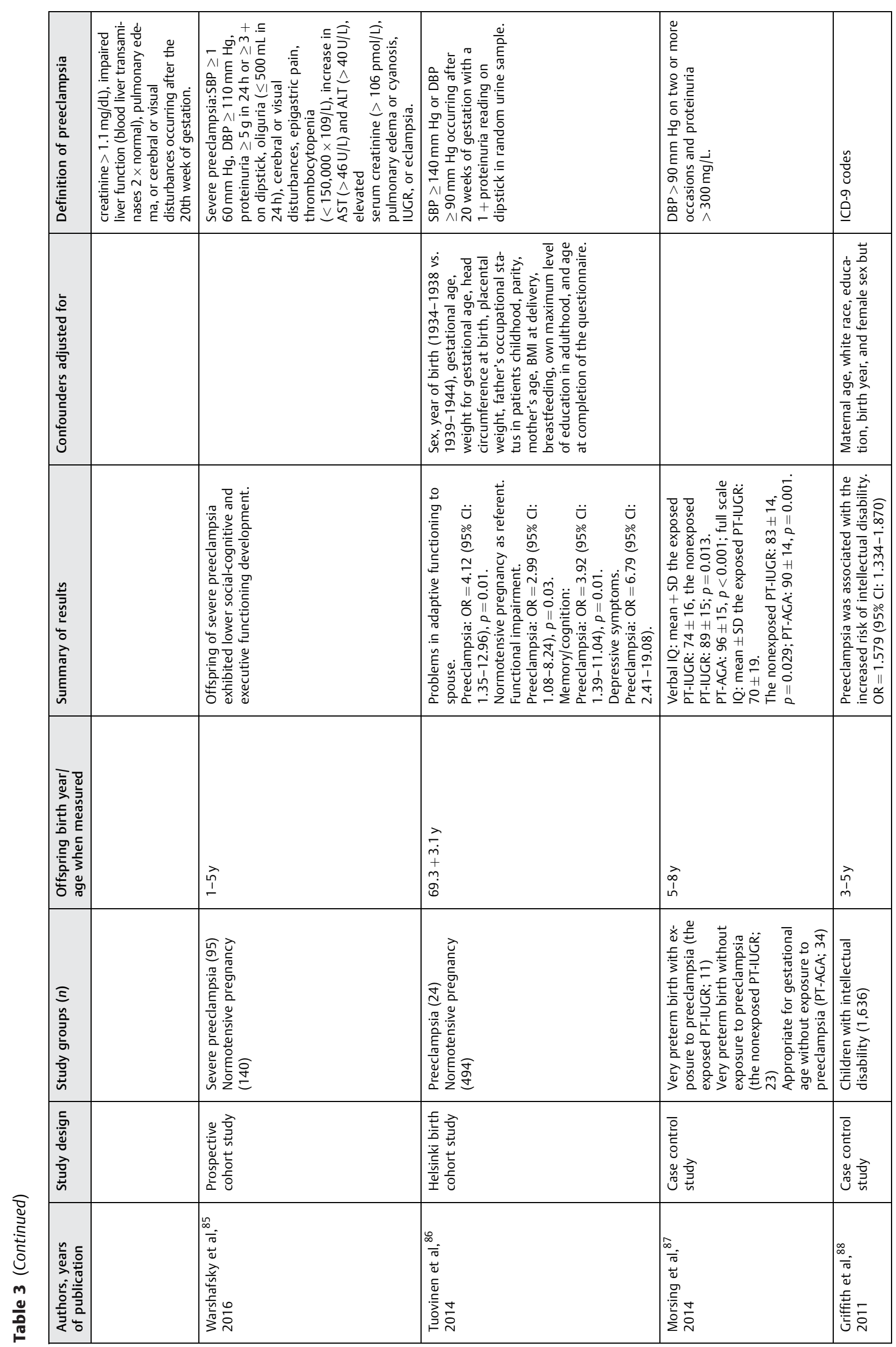




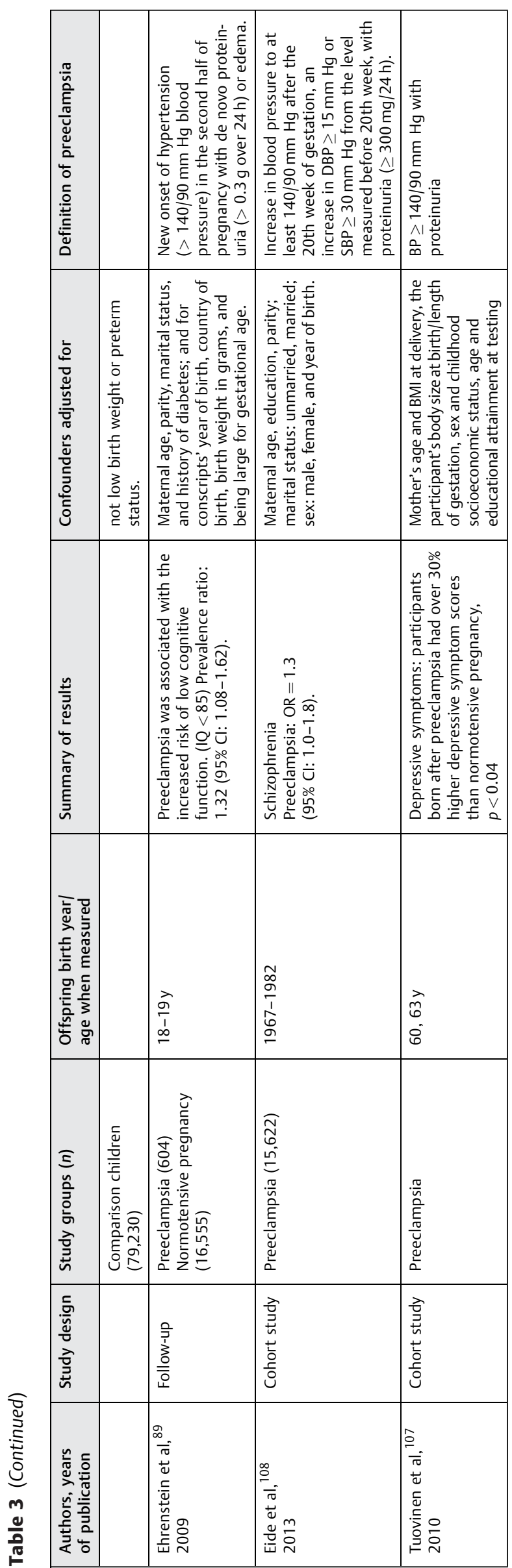

provided combined micronutrients supplementation to dams during pregnancy including folate, vitamin B12, and DHA (docosahexaenoic acid), all of which are key components of one carbon cycle and have been reported to be altered in the preeclamptic women, ${ }^{96}$ the levels of BDNF was higher and cognitive performance was improved. This study discovered an association between the deficiency of neurotrophins in the PIH offspring and impaired cognitive ability. ${ }^{97}$

A recent pilot study examined brain structural and vascular anatomy of 7 to 10 years old offspring exposed to preeclampsia compared with matched controls by magnetic resonance imaging (MRI). ${ }^{98}$ Researcher found offspring exposed to preeclampsia exhibited enlarged brain regional volume including the temporal lobe, cerebellum, brain stem, and the right and left amygdalae, as well as reduced vessel radii in the occipital and parietal lobes compared with matched controls, which are correlated with the psychometric test showing deficiency in working memory and visuaspatial processing in offspring exposed to preeclampsia. ${ }^{84}$ The alterations in brain structure above also shared similarities with those observed in autism. In addition, they showed a decreased level of placental growth factor in the maternal plasma samples from women with preeclampsia. ${ }^{98}$ Placental growth factor is a critical angiogenic cytokines expressed at increased level in normal pregnancy to optimize the development of vasculature in decidua basalis and sustain cardiac function in late gestation. ${ }^{99-101}$ The deficiency in maternal serum placental growth factor (PGF) is associated with an increased risk of preeclampsia which can serve to be a predictive biomarker of preeclampsia, especially when combined with elevated blood pressure and increased level of other antiangiogenic factors, such as soluble sFlt- $1 .^{102}$ Moreover, rodent studies have demonstrated the critical role of PGF in neurovascular development. Rätsep et al showed that genetically-deleted for placental growth factor mice had detectable alterations in the cerebrovascular including narrower lumen, atypical crossovers, and atypical collateral branching and brain neurological development from midgestation to adulthood, ${ }^{103}$ accompanied by impaired cognition. After injury, PGF deficient mice have30\% reduced Schwann's cells proliferation and significantly delayed macrophage invasion, leading to worse functional recovery. ${ }^{104}$ It has been reported that the timeframes of circle of Wills's formation and suboptimal production of PGF overlap in human. ${ }^{105}$ Therefore, it's reasonable to speculate that PGF deficiency in preeclampsia might impair fetal the cerebrovascular and brain neurological development and thus result in impaired cognitive ability. ${ }^{106}$ However, it should be noted that the deficiency of PGF in maternal plasma of preeclampsia does not mean that fetal PGF levels are lower than normal. Thus, further research are needed to clarify whether the level of fetal PGF is abnormal and its' exact role in altered cerebral and vascular structure and impaired cognitive function.

\section{PE and other Neurological Outcome in Offspring}

\section{Epidemiological Evidence}

Tuovinen et al also evaluated depressive symptoms in offspring exposed to preeclampsia. ${ }^{86,107}$ They found 
participants born after preeclampsia had over 30\% higher depressive symptom scores than normotensive pregnancy $(p<0.04)$ at the age of 60 and 63 years. ${ }^{107}$ Offspring aged 69.3 years exposed to preeclampsia were also at higher risk of having depressive symptoms (OR: 6.79 [95\%CI: 2.41-19.08]) after accounting for birth weight and gestational age. ${ }^{86}$ They were also at increased risk of having problems in adaptive functioning to spouse (OR: 4.12 [95\% CI: 1.35-12.96], $p=0.01){ }^{86}$ There was a study reporting a positive association between preeclampsia and schizophrenia in offspring. Eide et al conducted a population-based cohort study with large scale of population showed that offspring exposed to preeclampsia were at increased risks of schizophrenia and the risk was $37 \%$ higher compared with nonexposed offspring. ${ }^{108}$

\section{The Underlying Mechanism}

Preeclampsia is associated with reduced function of $11-\beta$ HSD-2 in placenta ${ }^{109}$ which can catalyze the conversion of maternal circulating cortisol into inactive cortisone. Therefore, fetus might be overexposed to maternal glucocorticoids which have the potential to program fetal HPA axis. The alteration in HPA axis is highly associated with biology underlying depression. ${ }^{110}$ However, the extent to which this mechanism is involved in the association between preeclampsia and increased risks of depression in offspring remains unanswered.

\section{Conclusion}

We not only made a review of epidemiological studies investigating lasting effects of preeclampsia on offspring but also comprehensively reviewed the possible mechanism. A large number of studies suggest that maternal preeclampsia has an overall negative effect on offspring cardiovascular and neurological health. Whereas, there is no significant difference in lipid profile and glucose metabolism between offspring born after preeclampsia and normotensive pregnancy. However, the agreement on the exact mechanism through which preeclampsia exert long-lasting effects on offspring has not been reached; therefore, further studies are needed to clarify it. Based on the epidemiological evidence, it is necessary to take the long-term health outcome of offspring into account in the clinical management of preeclampsia and early prevention and intervention strategies should be taken.

\section{Funding Information}

This study was supported by the National Natural Science Foundation of China 81571460.

\section{Conflict of Interests}

The Authors declare that there is no conflict of interest.

\section{References}

1 Brown MA, Magee LA, Kenny LC, et al; International Society for the Study of Hypertension in Pregnancy (ISSHP). The hypertensive disorders of pregnancy: ISSHP classification, diagnosis \& management recommendations for international practice. Pregnancy Hypertens 2018;13:291-310
2 Phipps EA, Thadhani R, Benzing T, Karumanchi SA. Pre-eclampsia: pathogenesis, novel diagnostics and therapies. Nat Rev Nephrol 2019; (e-pub ahead of print) . Doi: 10.1038/s41581-019-0119-6

$3 \mathrm{Lu} \mathrm{HQ}$ Hu R. The role of immunity in the pathogenesis and development of preeclampsia. Scand J Immunol 2019; (e-pub ahead of print) . Doi: $10.1111 /$ sji.12756

4 Lisonkova S, Joseph KS. Incidence of preeclampsia: risk factors and outcomes associated with early- versus late-onset disease. Am J Obstet Gynecol 2013;209(06):544.e1-544.e12

5 Amaral LM, Cunningham MW Jr., Cornelius DC, LaMarca B. Preeclampsia: long-term consequences for vascular health. Vasc Health Risk Manag 2015;11:403-415

6 Barker DJ. Adult consequences of fetal growth restriction. Clin Obstet Gynecol 2006;49(02):270-283

7 Barker DJ, Bagby SP, Hanson MA. Mechanisms of disease: in utero programming in the pathogenesis of hypertension. Nat Clin Pract Nephrol 2006;2(12):700-707

8 Alsnes IV, Vatten LJ, Fraser A, et al. Hypertension in pregnancy and offspring cardiovascular risk in young adulthood: prospective and sibling studies in the HUNT study (Nord-Trøndelag health study) in Norway. Hypertension 2017;69(04):591-598

9 Miliku K, Bergen NE, Bakker H, et al. Associations of maternal and paternal blood pressure patterns and hypertensive disorders during pregnancy with childhood blood pressure. JAm Heart Assoc 2016;5(10):e003884

10 Staley JR, Bradley J, Silverwood RJ, et al. Associations of blood pressure in pregnancy with offspring blood pressure trajectories during childhood and adolescence: findings from a prospective study. J Am Heart Assoc 2015;4(05):e001422

11 Fraser A, Nelson SM, Macdonald-Wallis C, Sattar N, Lawlor DA. Hypertensive disorders of pregnancy and cardiometabolic health in adolescent offspring. Hypertension 2013;62(03): 614-620

12 Miettola S, Hartikainen AL, Vääräsmäki M, et al. Offspring's blood pressure and metabolic phenotype after exposure to gestational hypertension in utero. Eur J Epidemiol 2013;28 (01):87-98

13 Lawlor DA, Macdonald-Wallis C, Fraser A, et al. Cardiovascular biomarkers and vascular function during childhood in the offspring of mothers with hypertensive disorders of pregnancy: findings from the Avon Longitudinal Study of Parents and Children. Eur Heart J 2012;33(03):335-345

14 Geelhoed JJ, Fraser A, Tilling K, et al. Preeclampsia and gestational hypertension are associated with childhood blood pressure independently of family adiposity measures: the Avon Longitudinal Study of Parents and Children. Circulation 2010;122(12): 1192-1199

15 Øglaend B, Forman MR, Romundstad PR, Nilsen ST, Vatten LJ. Blood pressure in early adolescence in the offspring of preeclamptic and normotensive pregnancies. JHypertens 2009;27 (10):2051-2054

16 Jayet PY, Rimoldi SF, Stuber T, et al. Pulmonary and systemic vascular dysfunction in young offspring of mothers with preeclampsia. Circulation 2010;122(05):488-494

17 Boyd HA, Basit S, Behrens I, et al. Association between fetal congenital heart defects and maternal risk of hypertensive disorders of pregnancy in the same pregnancy and across pregnancies. Circulation 2017;136(01):39-48

18 Timpka S, Macdonald-Wallis C, Hughes AD, et al. Hypertensive disorders of pregnancy and offspring cardiac structure and function in adolescence. J Am Heart Assoc 2016;5(11):e003906

19 Auger N, Fraser WD, Healy-Profitós J, Arbour L. Association between preeclampsia and congenital heart defects. JAMA 2015;314(15):1588-1598

20 Brodwall K, Leirgul E, Greve G, et al. Possible common aetiology behind maternal preeclampsia and congenital heart defects in the child: a cardiovascular diseases in Norway project study. Paediatr Perinat Epidemiol 2016;30(01):76-85 
21 Kajantie E, Eriksson JG, Osmond C, Thornburg K, Barker DJ. Preeclampsia is associated with increased risk of stroke in the adult offspring: the Helsinki birth cohort study. Stroke 2009;40(04): $1176-1180$

22 Nahum Sacks K, Friger M, Shoham-Vardi I, et al. Prenatal exposure to preeclampsia as an independent risk factor for long-term cardiovascular morbidity of the offspring. Pregnancy Hypertens 2018;13:181-186

23 Salonen Ros H, Lichtenstein P, Lipworth L, Cnattingius S. Genetic effects on the liability of developing pre-eclampsia and gestational hypertension. Am J Med Genet 2000;91(04):256-260

24 Bergvall N, Cnattingius S. Familial (shared environmental and genetic) factors and the foetal origins of cardiovascular diseases and type 2 diabetes: a review of the literature. J Intern Med 2008; 264(03):205-223

25 Zhou C, Zou QY, Li H, et al. Preeclampsia downregulates microRNAs in fetal endothelial cells: roles of miR-29a/c-3p in endothelial function. J Clin Endocrinol Metab 2017;102(09):3470-3479

26 Wlodek ME, Westcott K, Siebel AL, Owens JA, Moritz KM. Growth restriction before or after birth reduces nephron number and increases blood pressure in male rats. Kidney Int 2008;74(02): 187-195

27 Henley D, Brown S, Pennell C, Lye S, Torpy DJ. Evidence for central hypercortisolism and elevated blood pressure in adolescent offspring of mothers with pre-eclampsia. Clin Endocrinol (Oxf) 2016;85(04):583-589

28 Byers BD, Betancourt A, Lu F, et al. The effect of prepregnancy obesity and sFlt-1-induced preeclampsia-like syndrome on fetal programming of adult vascular function in a mouse model. Am J Obstet Gynecol 2009;200(04):432.e1-432.e7

29 Ojeda NB, Grigore D, Yanes LL, et al. Testosterone contributes to marked elevations in mean arterial pressure in adult male intrauterine growth restricted offspring. Am J Physiol Regul Integr Comp Physiol 2007;292(02):R758-R763

30 Ghorashi V, Sheikhvatan M. The relationship between serum concentration of free testosterone and pre-eclampsia. Endokrynol Pol 2008;59(05):390-392

31 Dharmashankar K, Widlansky ME. Vascular endothelial function and hypertension: insights and directions. Curr Hypertens Rep 2010;12(06):448-455

32 Lewandowski AJ, Davis EF, Yu G, et al. Elevated blood pressure in preterm-born offspring associates with a distinct antiangiogenic state and microvascular abnormalities in adult life. Hypertension 2015;65(03):607-614

33 Llurba E, Sánchez O, Ferrer Q et al. Maternal and foetal angiogenic imbalance in congenital heart defects. Eur Heart J 2014;35 (11):701-707

34 Roberts JM, Bell MJ. If we know so much about preeclampsia, why haven't we cured the disease? J Reprod Immunol 2013;99 $(1,2): 1-9$

35 Wlodek ME, Mibus A, Tan A, Siebel AL, Owens JA, Moritz KM. Normal lactational environment restores nephron endowment and prevents hypertension after placental restriction in the rat. J Am Soc Nephrol 2007;18(06):1688-1696

36 Singh RR, Denton KM, Bertram JF, Jefferies AJ, Moritz KM. Reduced nephron endowment due to fetal uninephrectomy impairs renal sodium handling in male sheep. Clin Sci (Lond) 2010;118(11):669-680

37 Grigore D, Ojeda NB, Robertson EB, et al. Placental insufficiency results in temporal alterations in the renin angiotensin system in male hypertensive growth restricted offspring. Am J Physiol Regul Integr Comp Physiol 2007;293(02):R804-R811

38 Zhang DY, Lumbers ER, Simonetta G, et al. Effects of placental insufficiency on the ovine fetal renin-angiotensin system. Exp Physiol 2000;85(01):79-84

39 Rasch R, Skriver E, Woods LL. The role of the RAS in programming of adult hypertension. Acta Physiol Scand 2004;181(04):537-542
40 Alwasel SH, Kaleem I, Sahajpal V, Ashton N. Maternal protein restriction reduces angiotensin II AT(1) and $\mathrm{AT}(2)$ receptor expression in the fetal rat kidney. Kidney Blood Press Res 2010;33(04):251-259

41 Manning J, Vehaskari VM. Low birth weight-associated adult hypertension in the rat. Pediatr Nephrol 2001;16(05):417-422

42 IJzerman RG, Stehouwer CD, de Geus EJ, van Weissenbruch MM, Delemarre-van de Waal HA, Boomsma DI. Low birth weight is associated with increased sympathetic activity: dependence on genetic factors. Circulation 2003;108(05):566-571

43 Sanders MW, Fazzi GE, Janssen GM, de Leeuw PW, Blanco CE, De Mey JG. Reduced uteroplacental blood flow alters renal arterial reactivity and glomerular properties in the rat offspring. Hypertension 2004;43(06):1283-1289

44 Rouwet EV, Tintu AN, Schellings MW, et al. Hypoxia induces aortic hypertrophic growth, left ventricular dysfunction, and sympathetic hyperinnervation of peripheral arteries in the chick embryo. Circulation 2002;105(23):2791-2796

45 Maduwegedera D, Kett MM, Flower RL, et al. Sex differences in postnatal growth and renal development in offspring of rabbit mothers with chronic secondary hypertension. Am J Physiol Regul Integr Comp Physiol 2007;292(02):R706-R714

46 Alexander BT, Hendon AE, Ferril G, Dwyer TM. Renal denervation abolishes hypertension in low-birth-weight offspring from pregnant rats with reduced uterine perfusion. Hypertension 2005;45 (04):754-758

47 Salamalekis E, Bakas P, Vitoratos N, Eleptheriadis M, Creatsas G. Androgen levels in the third trimester of pregnancy in patients with preeclampsia. Eur J Obstet Gynecol Reprod Biol 2006;126 (01):16-19

48 Sathishkumar K, Elkins R, Yallampalli U, Balakrishnan M, Yallampalli C. Fetal programming of adult hypertension in female rat offspring exposed to androgens in utero. Early Hum Dev 2011;87(06):407-414

49 Chinnathambi V, Balakrishnan M, Yallampalli C, Sathishkumar K. Prenatal testosterone exposure leads to hypertension that is gonadal hormone-dependent in adult rat male and female offspring. Biol Reprod 2012;86(05):137, 1-7

$50 \mathrm{Wu} \mathrm{XY,} \mathrm{Li} \mathrm{ZL,} \mathrm{Wu} \mathrm{CY,} \mathrm{et} \mathrm{al.} \mathrm{Endocrine} \mathrm{traits} \mathrm{of} \mathrm{polycystic} \mathrm{ovary}$ syndrome in prenatally androgenized female Sprague-Dawley rats. Endocr J 2010;57(03):201-209

51 More AS, Mishra JS, Hankins GD, Kumar S. Prenatal testosterone exposure decreases aldosterone production but maintains normal plasma volume and increases blood pressure in adult female rats. Biol Reprod 2016;95(02):42

52 Jiménez-Chillarón JC, Díaz R, Martínez D, et al. The role of nutrition on epigenetic modifications and their implications on health. Biochimie 2012;94(11):2242-2263

53 Orozco LD, Rubbi L, Martin LJ, et al. Intergenerational genomic DNA methylation patterns in mouse hybrid strains. Genome Biol 2014;15(05):R68

$54 \mathrm{Hu}$ W, Weng X, Dong M, Liu Y, Li W, Huang H. Alteration in methylation level at $11 \beta$-hydroxysteroid dehydrogenase type 2 gene promoter in infants born to preeclamptic women. BMC Genet 2014;15:96

55 Aufdenblatten M, Baumann M, Raio L, et al. Prematurity is related to high placental cortisol in preeclampsia. Pediatr Res 2009;65(02):198-202

56 Bourque DK, Avila L, Peñaherrera M, von Dadelszen P, Robinson WP. Decreased placental methylation at the H19/IGF2 imprinting control region is associated with normotensive intrauterine growth restriction but not preeclampsia. Placenta 2010;31(03):197-202

57 Ching T, Ha J, Song MA, et al. Genome-scale hypomethylation in the cord blood DNAs associated with early onset preeclampsia. Clin Epigenetics 2015;7:21

58 Wang X, Wan L, Weng X, et al. Alteration in methylation level at differential methylated regions of MEST and DLK1 in fetus of preeclampsia. Hypertens Pregnancy 2018;37(01):1-8 
59 Blair JD, Yuen RK, Lim BK, McFadden DE, von Dadelszen P, Robinson WP. Widespread DNA hypomethylation at gene enhancer regions in placentas associated with early-onset pre-eclampsia. Mol Hum Reprod 2013;19(10):697-708

60 Hromadnikova I, Kotlabova K, Ivankova K, Vedmetskaya Y, Krofta L. Profiling of cardiovascular and cerebrovascular disease associated microRNA expression in umbilical cord blood in gestational hypertension, preeclampsia and fetal growth restriction. Int J Cardiol 2017;249:402-409

61 Lazdam M, de la Horra A, Diesch J, et al. Unique blood pressure characteristics in mother and offspring after early onset preeclampsia. Hypertension 2012;60(05):1338-1345

62 Alsnes IV, Janszky I, Forman MR, Vatten LJ, Økland I. A population-based study of associations between preeclampsia and later cardiovascular risk factors. Am J Obstet Gynecol 2014;211(06): 657.e1-657.e7

63 Seppä S, Voutilainen R, Tenhola S. Markers of insulin sensitivity in 12-year-old children born from preeclamptic pregnancies. J Pediatr 2015;167(01):125-130

64 Kajantie E, Osmond C, Eriksson JG. Gestational hypertension is associated with increased risk of type 2 diabetes in adult offspring: the Helsinki Birth Cohort Study. Am J Obstet Gynecol 2017;216(03):281.e1-281.e7

65 Walker CK, Krakowiak P, Baker A, Hansen RL, Ozonoff S, HertzPicciotto I. Preeclampsia, placental insufficiency, and autism spectrum disorder or developmental delay. JAMA Pediatr 2015;169(02):154-162

66 Mann JR, McDermott S, Bao H, Hardin J, Gregg A. Pre-eclampsia, birth weight, and autism spectrum disorders. JAutism Dev Disord 2010;40(05):548-554

67 Burstyn I, Sithole F, Zwaigenbaum L. Autism spectrum disorders, maternal characteristics and obstetric complications among singletons born in Alberta, Canada. Chronic Dis Can 2010;30 (04):125-134

68 Buchmayer S, Johansson S, Johansson A, Hultman CM, Sparén P, Cnattingius S. Can association between preterm birth and autism be explained by maternal or neonatal morbidity? Pediatrics 2009;124(05):e817-e825

69 Silva D, Colvin L, Hagemann E, Bower C. Environmental risk factors by gender associated with attention-deficit/hyperactivity disorder. Pediatrics 2014;133(01):e14-e22

70 Getahun D, Rhoads GG, Demissie K, et al. In utero exposure to ischemic-hypoxic conditions and attention-deficit/hyperactivity disorder. Pediatrics 2013;131(01):e53-e61

71 Halmøy A, Klungsøyr K, Skjærven R, Haavik J. Pre- and perinatal risk factors in adults with attention-deficit/hyperactivity disorder. Biol Psychiatry 2012;71(05):474-481

72 Amiri S, Malek A, Sadegfard M, Abdi S. Pregnancy-related maternal risk factors of attention-deficit hyperactivity disorder: a case-control study. ISRN Pediatr 2012;2012:458064

73 Mann JR, McDermott S. Are maternal genitourinary infection and pre-eclampsia associated with ADHD in school-aged children? J Atten Disord 2011;15(08):667-673

74 Tolsa CB, Zimine S, Warfield SK, et al. Early alteration of structural and functional brain development in premature infants born with intrauterine growth restriction. Pediatr Res 2004;56 (01):132-138

75 Mallard EC, Rees S, Stringer M, Cock ML, Harding R. Effects of chronic placental insufficiency on brain development in fetal sheep. Pediatr Res 1998;43(02):262-270

76 Batty MJ, Liddle EB, Pitiot A, et al. Cortical gray matter in attention-deficit/hyperactivity disorder: a structural magnetic resonance imaging study. JAm Acad Child Adolesc Psychiatry 2010;49(03):229-238

77 Carmona S, Vilarroya O, Bielsa A, et al. Global and regional gray matter reductions in ADHD: a voxel-based morphometric study. Neurosci Lett 2005;389(02):88-93
78 Miguel PM, Schuch CP, Rojas JJ, et al. Neonatal hypoxia-ischemia induces attention-deficit hyperactivity disorder-like behavior in rats. Behav Neurosci 2015;129(03):309-320

79 Curran EA, O'Keeffe GW, Looney AM, et al. Exposure to hypertensive disorders of pregnancy increases the risk of autism spectrum disorder in affected offspring. Mol Neurobiol 2018;55(07):5557-5564

80 Choi GB, Yim YS, Wong H, et al. The maternal interleukin-17a pathway in mice promotes autism-like phenotypes in offspring. Science 2016;351(6276):933-939

81 Darmochwal-Kolarz D, Kludka-Sternik M, Tabarkiewicz J, et al. The predominance of Th17 lymphocytes and decreased number and function of Treg cells in preeclampsia. JReprod Immunol 2012;93(02):75-81

82 Wu WL, Hsiao EY, Yan Z, Mazmanian SK, Patterson PH. The placental interleukin-6 signaling controls fetal brain development and behavior. Brain Behav Immun 2017;62:11-23

83 Jones KL, Croen LA, Yoshida CK, et al. Autism with intellectual disability is associated with increased levels of maternal cytokines and chemokines during gestation. Mol Psychiatry 2017;22 (02):273-279

84 Rätsep MT, Hickman AF, Maser B, et al. Impact of preeclampsia on cognitive function in the offspring. Behav Brain Res 2016; 302:175-181

85 Warshafsky C, Pudwell J, Walker M, Wen SW, Smith GN; Preeclampsia New Emerging Team. Prospective assessment of neurodevelopment in children following a pregnancy complicated by severe pre-eclampsia. BMJ Open 2016;6(07):e010884

86 Tuovinen S, Aalto-Viljakainen T, Eriksson JG, et al. Maternal hypertensive disorders during pregnancy: adaptive functioning and psychiatric and psychological problems of the older offspring. BJOG 2014;121(12):1482-1491

87 Morsing E, Maršál K. Pre-eclampsia- an additional risk factor for cognitive impairment at school age after intrauterine growth restriction and very preterm birth. Early Hum Dev 2014;90(02):99-101

88 Griffith MI, Mann JR, McDermott S. The risk of intellectual disability in children born to mothers with preeclampsia or eclampsia with partial mediation by low birth weight. Hypertens Pregnancy 2011;30(01):108-115

89 Ehrenstein V, Rothman KJ, Pedersen L, Hatch EE, Sørensen HT. Pregnancy-associated hypertensive disorders and adult cognitive function among Danish conscripts. Am J Epidemiol 2009; 170(08):1025-1031

90 Liu X, Zhao W, Liu H, et al. Developmental and functional brain impairment in offspring from preeclampsia-like rats. Mol Neurobiol 2016;53(02):1009-1019

91 Akande VO, Hendriks AM, Ruiter RA, Kremers SP. Determinants of dietary behavior and physical activity among Canadian Inuit: a systematic review. Int J Behav Nutr Phys Act 2015;12:84

92 Zhu H, Zhu W, Hu R, Wang H, Ma D, Li X. The effect of preeclampsia-like syndrome induced by L-NAME on learning and memory and hippocampal glucocorticoid receptor expression: A rat model. Hypertens Pregnancy 2017;36(01):36-43

93 Nyaradi A, Li J, Hickling S, Foster J, Oddy WH. The role of nutrition in children's neurocognitive development, from pregnancy through childhood. Front Hum Neurosci 2013;7:97

94 Rathod RS, Khaire AA, Kale AA, Joshi SR. Beneficial effects of omega-3 fatty acids and vitamin B12 supplementation on brain docosahexaenoic acid, brain derived neurotrophic factor, and cognitive performance in the second-generation Wistar rats. Biofactors 2015;41(04):261-272

95 Sharma S, Zhuang Y, Gomez-Pinilla F. High-fat diet transition reduces brain DHA levels associated with altered brain plasticity and behaviour. Sci Rep 2012;2:431

96 Wadhwani NS, Narang AS, Mehendale SS, Wagh GN, Gupte SA, Joshi SR. Reduced maternal erythrocyte long chain polyunsaturated fatty acids exist in early pregnancy in preeclampsia. Lipids 2016;51(01):85-94 
97 Kemse N, Kale A, Chavan-Gautam P, Joshi S. Increased intake of vitamin $B_{12}$, folate, and omega- 3 fatty acids to improve cognitive performance in offspring born to rats with induced hypertension during pregnancy. Food Funct 2018;9(07):3872-3883

98 Rätsep MT, Paolozza A, Hickman AF, et al. Brain structural and vascular anatomy is altered in offspring of pre-eclamptic pregnancies: a pilot study. AJNR Am J Neuroradiol 2016;37(05):939-945

99 Carmeliet P, Ferreira V, Breier G, et al. Abnormal blood vessel development and lethality in embryos lacking a single VEGF allele. Nature 1996;380(6573):435-439

100 Aasa KL, Zavan B, Luna RL, et al. Placental growth factor influences maternal cardiovascular adaptation to pregnancy in mice. Biol Reprod 2015;92(02):44

101 Vrachnis N, Kalampokas E, Sifakis S, et al. Placental growth factor (PIGF): a key to optimizing fetal growth. J Matern Fetal Neonatal Med 2013;26(10):995-1002

102 Powers RW, Roberts JM, Plymire DA, et al. Low placental growth factor across pregnancy identifies a subset of women with preterm preeclampsia: type 1 versus type 2 preeclampsia? Hypertension 2012;60(01):239-246

103 Rätsep MT, Carmeliet P, Adams MA, Croy BA. Impact of placental growth factor deficiency on early mouse implant site angiogenesis. Placenta 2014;35(09):772-775
104 Chaballe L, Close P, Sempels M, et al. Involvement of placental growth factor in Wallerian degeneration. Glia 2011;59(03): 379-396

105 Luna RL, Kay VR, Rätsep MT, et al. Placental growth factor deficiency is associated with impaired cerebral vascular development in mice. Mol Hum Reprod 2016;22(02):130-142

106 Dang F, Croy BA, Stroman PW, Figueiró-Filho EA. Impacts of preeclampsia on the brain of the offspring. Rev Bras Ginecol Obstet 2016;38(08):416-422

107 Tuovinen S, Räikkönen K, Kajantie E, et al. Depressive symptoms in adulthood and intrauterine exposure to pre-eclampsia: the Helsinki Birth Cohort Study. BJOG 2010;117(10): 1236-1242

108 Eide MG, Moster D, Irgens LM, et al. Degree of fetal growth restriction associated with schizophrenia risk in a national cohort. Psychol Med 2013;43(10):2057-2066

109 Kajantie E, Dunkel L, Turpeinen U, et al. Placental 11 betahydroxysteroid dehydrogenase-2 and fetal cortisol/cortisone shuttle in small preterm infants. J Clin Endocrinol Metab 2003; 88(01):493-500

110 Brown ES, Varghese FP, McEwen BS. Association of depression with medical illness: does cortisol play a role? Biol Psychiatry 2004;55(01):1-9 